\title{
Evolução da atmosfera de loja e suas contribuições na ressignificação do visual merchandising de moda
}

Store atmospherics evolution and its contributions to the re-significa-
tion of fashion visual merchandising

SILVA, José Eduardo Vilas Bôas

Universidade de São Paulo - USP I eduardo.vilasboas@gmail.com

CRESCITELLI, Edson

Universidade de São Paulo - USP I edsonc@usp.br

ALVAREZ, Francisco Javier Sebastian Mendizabal

Universidade de São Paulo - USP I falvarez@usp.br

\begin{abstract}
Resumo
Este artigo tem por objetivo estabelecer de forma cronológica a evolução histórica da atmosfera de loja dos espaços comerciais destinados à comercialização de artigos têxteis e de moda a fim de compreender-se os resultados do impacto dessas alterações no conceito e nos objetivos do visual merchandising ao longo do tempo. O resultado culminou na produção de uma timeline de cinco fases (estrutural, empírica, expansionista, experiencial e eletrônica) com a qual é possível compreender as razões das alterações e expansão do escopo de visual merchandising na contemporaneidade.
\end{abstract}

Palavras-chave: Visual merchandising. Atmosfera de loja. Comunicação de marketing. Varejo de moda.

\section{Abstract}

This paper aims to establish the historical and chronological evolution of store atmospherics in textile and fashion retail spaces in order to understand the impact of this strategy on the store concept and on the objectives of visual merchandising along time. The result of this study is the design of a timeline divided in five stages (structural, empirical, expansionary, experiential, and electronic) in which it is possible to understand the current reasons for changes and expansion in the scope of visual merchandising.

Keywords: Visual merchandising. Store atmospherics. Marketing communication. Fashion retail. 


\section{INTRODUC̣ÃO}

A partir do século $X X$ há uma forte tendência pela procura do visual merchandising (VM) como uma ferramenta de comunicação mercadológica capaz de agregar valores para as marcas de moda, motivadas pelo aceleramento do ciclo de vida dos produtos, pela disseminação de uma cultura hedonista e visual, pelo aumento da concorrência no varejo, além da homogeneização estética e banalização dos produtos (SACKRIDER et al., 2009).

Por tratar-se de uma ferramenta essencialmente mercadológica, os estudos acadêmicos e a teorização sobre visual merchandising ainda são escassos e, por isso, replicam-se conceitos datados que não refletem a prática contemporânea do objeto, tão menos justificam sua relevância e complexidade. Tal qual afirmam Ebster et al. $(2013$, p.3) "o fato de que a maioria das decisões de compra são tomadas ou influenciadas pelo ambiente da loja faz do ponto de venda (PDV) uma ferramenta de marketing ideal $[. .]$.$" .$

Por esta razão o PDV tornou-se relevante para os estudos acadêmicos. Kotler (1973) estabeleceu o conceito de atmosfera de loja como o planejamento consciente de atmosferas no espaço comercial para contribuir no favorecimento das compras. Sua definição é a premissa para todos os estudos que se seguem sobre a influência do PDV no comportamento de compra, tais como Berman e Evans (1995) e Turley e Milliman (2000), os quais propuseram uma revisão do escopo da atmosfera de loja resultando no espectro de 57 variáveis.

Deste modo, a partir da metodologia de revisão bibliográfica, esse artigo objetiva estabelecer de forma cronológica a evolução histórica dos espaços comerciais destinados à comercialização de artigos têxteis e de moda para compreender-se os resultados do impacto dessas alterações no conceito e nos objetivos do visual merchandising ao longo do tempo.

Assim, o resultado dessa pesquisa culminou numa timeline de cinco fases distintas, na qual é possível compreender os objetivos e alterações do escopo de visual merchandising conforme a evolução do varejo.

Essa compreensão se faz urgente e significativa pois reflete as alterações nas relações de consumo e produção industrial, bem como poderá nortear novos estudos acadêmicos, respaldando a ferramenta como um campo notório do saber.

\section{DESENVOLVIMENTO}

A definição de Kotler (1973) sobre atmosfera de loja iniciou as discussões sobre a importância dos estímulos projetados no espaço comercial a fim de influenciar e motivar os consumidores, além de elevar o PDV a condição de criar 
diferencial competitivo para as marcas frente a comoditização e banalização dos produtos.

Kotler (1973) salienta que a atmosfera de loja é o recurso de marketing mais destacado para as marcas que ofertam produtos com design, marcas que tenham loja física, mercados altamente concorridos, quando há pouca diferença dos produtos entre a concorrência e quando existe um lifestyle evidente no público-alvo. Por isso, o PDV é capaz de afetar o comportamento do consumidor através de elementos e qualidades sensoriais perceptíveis, que vão atuar na sua atenção, distorção e retenção seletiva, alterando seu estado afetivo e informativo, o que tende a aumentar sua disposição à compra.

Berman e Evans (1995) descreveram esses elementos e estímulos da atmosfera de loja e os organizaram em quatro grupos de variáveis: (I) as variáveis externas à loja, (II) as variáveis gerais do interior, (III) as variáveis do layout e do design e (IV) as variáveis do ponto de venda e decoração. Buscando complementar essa descrição, Turley e Milliman (2000) expandiram o escopo para cinco categorias, adicionando as $(V)$ variáveis humanas, o que configurou 57 elementos e estímulos inerentes a atmosfera de loja.

As decisões sobre o escopo de atmosfera de loja foram, durante décadas, tomadas pelos varejistas de forma arbitrária, desconexa e isolada. O visual merchandising ao assumir a responsabilidade de gerir e integrar essas 57 variáveis tem sido apontado como um dos principais pontos de contato do Composto de Marketing, de forma a permitir a materialização para o consumidor dos valores de uma marca e demais aspetos intangíveis da comunicação. Crescitelli e Shimp (2012) endossam que:

Os profissionais de marketing astutos percebem que 0 ambiente de loja é a última e melhor chance de fazer diferença. A comunicação no PDV, com frequência, representa o ponto culminante de um programa de CIM [Comunicação Integrada de Marketing] cuidadosamente integrado (CRESCITELLI; SHIMP, 2012, p.495).

Essa conversão do intangível da marca em atributos tangíveis e comunicáveis visa aumentar o brand equity e trabalhar os estímulos necessários a um consumidor hedonista, o que pode ser compreendido em momentos de prazer, relaxamento, entretenimento e escapismo.

Morgan (2011), numa visão mais contemporânea, trata o visual merchandising e design de lojas como um único conceito: "o design de lojas reúne todos os aspectos do visual merchandising: vitrines e interiores, instalações, mobiliários, acessórios e iluminação" (p.30), isto é, a atmosfera de loja descrita por Turley e Milliman (2000). 
Para Bailey e Baker (2014, p.10) "a atividade de visual merchandising deve ser vista como um processo que se estende desde o conceito até a finalização e que tem como propósito criar uma identidade clara da marca". Para os referidos autores, é papel do visual merchandiser criar o ponto de diferenciação entre as marcas, haja vista a comoditização dos artigos de moda.

Portanto, o conceito de visual merchandising vai além do difundido e histórico conceito de apresentar a amplitude do mix de produtos no PDV. Ele deve comunicar a identidade e enriquecer o perfil da marca, provocando impacto e atração visual de forma que chame a atenção dos clientes e os atraiam para dentro da loja; criando uma atmosfera, simplificando a experiência de compra, gerando oportunidades de divulgações, maximizando o aproveitamento do espaço comercial para, consequentemente, aumentar as vendas (BAILEY; BAKER, 2014).

Sackrider et al. (2008) também concordam ao afirmar que o visual merchandising é frequentemente apresentado como uma parte do marketing, com uma eventual noção de hierarquia que situa o primeiro no nível das consequências práticas do segundo (disposição de vitrinas, decoração, apresentação dos produtos), sendo que, na realidade atual, o visual merchandising como catalisador da compra e vetor da identidade da marca através do PDV está em contato direto com o marketing, tomado em seu sentido mais amplo, colocando-se, inclusive, bem no início de sua reflexão.

Logo, pode-se afirmar que o visual merchandising é hoje uma ferramenta complexa e abrangente dentro do Composto de Comunicação capaz de gerar diferencial competitivo ao conformar a atmosfera de loja e, portanto, estratégico para o varejo de moda.

Sendo assim, pode-se entender que o visual merchandising na atualidade é responsável pelo design global das lojas e pelo tangível da experiência de compras, abrangendo desde a comunicação externa que afeta a percepção e reconhecimento da marca, como sinalização, fachada, arquitetura e vitrinas, passando pela coordenação e valorização de produtos no mobiliário (exibitécnica), até fatores relativos à operação comercial, como a seleção de produtos para apresentação e a alocação de espaços conforme demanda de vendas e amplitude do mix de produtos.

\subsection{Análise da Evolução do Varejo de Moda}

Uma análise sobre a evolução histórica do varejo de moda pode evidenciar como as práticas comerciais alteraram e diversificaram o escopo da atmosfera de loja. Assim, a partir dessa revisão bibliográfica pode-se compreender a evolução do visual merchandising por meio do desenvolvimento do varejo em cinco grandes fases. 
A classificação proposta não visa esgotar o assunto ou engessá-lo, mas fundamentar uma argumentação que evidencie as mudanças conceituais e pragmáticas que sofreu o varejo de moda influenciando e conformando o conceito contemporâneo de visual merchandising.

\subsubsection{Primeira Fase - Estrutural (séc. XI a 1851)}

Após fixar-se à terra, abandonando o estilo de vida nômade, o homem pôde construir núcleos sociais mais complexos, o que demandou produtos diversificados a sua sobrevivência. Os indivíduos perceberam, então, que sendo especialistas na produção de bens teriam maior vantagem em suas trocas, tanto em função da qualidade como da quantidade produzida (LAS CASAS, 1994).

Conforme afirma Las Casas (1994, p. 13) "começou assim a comercialização e a formação de mercados. Surgiram a moeda e os intermediários como facilitadores do processo de trocas". Exemplo fundamental de mercado precursor é ágora, "praça central de comércio na antiga Atenas, [onde] os vendedores se agrupavam segundo os ramos de negócio. [...] "Mais do que apenas um mercado, a ágora era o coração de Atenas" (MCMILLAN, 2004).

Porém, segundo Williams (20177) foi com as Cruzadas, a partir de 1095, que de fato as pessoas puderam obter lucro do comércio. Dessa forma, o ponto de partida deste estudo é a condição para haver o comércio, ou seja, quando existe procura e incentivo para escoar mercadorias, o que se deu com as Cruzadas, a partir do século XI. E a primeira fase na evolução da atmosfera de loja refere-se a esse período embrionário do varejo, que vai refletir em questões estruturais básicas para o ponto de venda, que lhe conferem um ambiente mínimo de valorização dos produtos e atenção às compras.

Do século $X I$ até o final do século XVIII, os varejistas pouco se importavam com a aparência de suas lojas e a apresentação das mercadorias. Poucos produtos do portfólio eram expostos e a venda era intermediada por um balcão e atendente, o que direcionava as vendas conforme os interesses do comerciante (BHALLA; SINGHAL, 2010).

Segundo Bhalla e Singhal (2010) o primeiro passo mais significativo na evolução da atmosfera de loja ocorreu quando pequenas lojas começaram a mostrar suas mercadorias abertas ao público, em vez de mantê-las guardadas em salas. Assim, alguns exibiam letreiros, produtos em vitrines ou em mesas do lado de fora do comércio, "dessa forma, mostravam ao público que o estabelecimento estava aberto e que se orgulhavam de seus produtos" (MORGAN, 2011, p.11). 
Os avanços tecnológicos do período também refletiram na atmosfera de loja. O primeiro, em 1840, referiu-se à possibilidade de produzir-se vidraças de grandes dimensões, o que permitiu os lojistas expor seus produtos em vitrinas. Morgan (2011, p.11) diz que as lojas "puderam dar um passo na arte de expor em vitrines, usando esses amplos espaços como verdadeiros cenários, alguns tão teatrais como um espetáculo da Broadway".

O segundo avanço tecnológico no processo de evolução da atmosfera de loja ocorreu na Europa durante o início do século XIX através do desenvolvimento das arcadas. Também chamadas de passagens, foram coberturas de ruas construídas com ferro e vidro. Segundo Benjamin (2002) a experimentação com novos materiais melhorou a qualidade estética das lojas que estavam alojadas dentro das arcadas.

A principal característica das arcadas foram as claraboias de vidro, que muitas vezes se estendiam por todo o comprimento do corredor, proporcionando um ambiente completamente fechado e visualmente estimulante para as compras. No entanto, as claraboias eram caras e causaram muitas dificuldades técnicas quanto a execução e sua área comercial visualmente atraente geralmente não se estendia para dentro das lojas.

Logo as arcadas tornaram-se associadas principalmente com os observadores que estavam apenas a andar ao redor - ato de flâneur - e não necessariamente a procura de produtos, conforme elucida Benjamin (2002), mas, assim, também se fomentou a compra por oportunidade e conveniência.

\subsubsection{Segunda Fase - Empírica (1851 a 1948)}

A segunda fase na evolução da atmosfera de loja pode ser compreendida através do legado das Exposições Universais e das Lojas de Departamento que desenvolveram técnicas de exposição de produtos a partir de experimentações empíricas.

As reflexões iniciais sobre a necessidade de parâmetros para uma exposição, orientação e sinalização de produtos na sua comercialização vieram com o advento das Exposições Universais, exatamente em meados do século XIX, parâmetros estes que até hoje embasam várias das práticas do visual merchandising.

Ainda que impulsionadas por uma indústria e comércio aquecidos pela recente Revolução Industrial, e repletos de novidades que precisavam ser apresentadas de forma valorizada para o público, as Exposições Universais venderam mais do que simplesmente produtos, venderam valores, explica Barbuy (1999, p. 40): "o que se vendia era - sim - um gênero de vida, uma 
construção política e ideológica, e visões de uma sociedade futura idealizada", e pautada no consumo, conforme desejava a burguesia industrial.

A magnitude das Exposições Universais trouxe a problemática da apresentação dos produtos, que foi solucionada pela setorização, agrupando conforme a área de produção ou a técnica de manufatura e, em cada grupo, organizavam-se por fabricantes. Essas indústrias eram provenientes de diversos países e seus stands eram inspirados na temática cultural e estética do seu local de origem, buscando associações ao conceito de marca-país. Por isso, as exposições criavam uma atmosfera de uma terra distante e exótica, conforme afirma Maurice Talmeyr, um importante crítico social e jornalista, sobre a Exposição Universal de Paris, em 1900:

\begin{abstract}
[A Exposição Universal continha] templos hindus, cabanas selvagens, pagodas, souks, becos argelinos, chinês, japonês, sudaneses, senegaleses, siameses, quartos cambojanos. Um bazar de climas, estilos arquitetônicos, cheiros, cores, gastronomia, [e] música... (TALMEYR apud WILLIAMNS, 1982, p.61, tradução nossa)
\end{abstract}

Nas palavras de Benjamin (apud BARBUY, 1999, p. 70) “[...] os olhos têm mil coisas para ver". E nesse rico contexto que o campo de formação da cultura visual configurou-se. "Há nesta ideia a evidência de uma nova constituição perceptiva onde o sentido da visão é privilegiado e reverenciado como porta de entrada de uma formulação social [...]" (KOSMINSKY et al. 2008, p.224).

\begin{abstract}
As Exposições Universais apresentam-se como um campo de formação da cultura visual, seja na arquitetura - construída especialmente para o evento ou como parte de uma exibição específica - na ornamentação e no design dos produtos expostos, na organização dos produtos exibidos, e, por fim, nas discussões contemporâneas que acompanharam estas exibições caracterizando, muitas vezes, a pedagogia de uma visualidade onde todos os elementos anteriores mesclam-se em uma ampla formulação (KOSMINSKY et al. 2008, p.224)
\end{abstract}

Tanto o apelo visual como outras técnicas desenvolvidas pelos expositores das Exposições Universais interferiram de forma direta no visual merchandising praticado pelo varejo de moda que se desenvolveu a partir de 1948, na França, com a instituição do modelo de gestão do prêt-à-porter (LEÃO, 2001).

Pegler (2000) afirma que as lojas de departamento como a Le Bon Marchè em Paris, desde 1838; a Selfridges em Londres, desde 1909; a Macy's em Nova York, desde 1858; Marshall Field's em Chicago, desde 1865; Bloomingdale's em Nova York, desde 1872 e Wanamaker na Filadélfia, 
desde 1876; influenciaram decisivamente o conceito e as práticas de visual merchandising em quatro aspectos.

Primeiro, ainda inspirados pelas Exposições Universais, mostrar a mercadoria foi um dos aspectos mais importantes da experiência de compras, pois até então os produtos sempre estavam estocados em caixas de transporte ou balcões de venda. Os varejistas foram capazes não só de elevar os produtos ao nível dos olhos e ao toque das mãos, como puderam testar o que funcionava melhor na exposição do produto enquanto os consumidores circulavam pelo PDV.

A segunda transformação se deu no uso do luxo no design de interiores. Os varejistas utilizaram muitas das mesmas técnicas e materiais empregados na construção das arcadas, em um esforço para trazer a beleza e conforto do exterior para o interior do PDV. Essas primeiras lojas de departamento queriam exalar um sentimento de luxo, vinculado ao ideal de um padrão de vida, através de lustres, vitrais, mármore, tapetes orientais, madeira polida, obras de arte e vários outros excessos também empregados nas Exposições Universais.

Em terceiro, em um esforço para transmitir aos consumidores que o abastecimento de mercadorias era abundante, os varejistas expuseram seus produtos de forma excessiva e caótica. Essa sensação de excesso despertava no consumidor o desejo de compra, tudo pelo medo do desabastecimento ocasionado pelas frequentes guerras e crises da época.

No último e quarto aspecto, as lojas de departamentos do século XIX continuaram e aperfeiçoaram o uso de ambientes temáticos, semelhantes aos que foram usados nas Exposições Universais. Nessa época, a posse de itens exóticos de lugares como África e Oriente Próximo, tornou-se moda. No entanto, os autênticos artefatos exóticos eram muito caros. As lojas de departamento expunham produtos genéricos, de valor mais acessível, com a intenção de aumentar a percepção de valor do consumidor.

\subsubsection{Terceira Fase - Expansionista (1948 a 1980)}

A terceira fase pode ser entendida como expansionista pois é o momento histórico no qual a moda deixa de ser propriedade exclusiva das elites e passa a ser comercializada de forma ostensiva através do grande varejo que se desenvolvia. Até o século $X X$, comprar roupas prontas não era uma prática comum, tão pouco se tratava de uma atividade industrial vantajosa.

Com o advento do prêt-à-porter surgem novos e diversificados tipos de lojas que buscam ofertar uma imagem sofisticada. Desenvolve-se também, como afirma Leão (2001), a profissionalização das carreiras relativas a produção 
e comercialização de moda. Sackrider et al. (2008) explicam que "quase inexistente na França até os anos 1970, [o visual merchandising] desenvolveuse por intermédio de algumas empresas multinacionais que o praticavam desde os anos 1960, principalmente nos EUA". Blessa (2009) vincula ainda a conformação do visual merchandising o surgimento do conceito de marketing e da intensificação do autosserviço nos Estados Unidos da América (EUA), na década de 1930. Isto é, o desenvolvimento do conceito de atmosfera de loja ascende do patamar operacional ao patamar estratégico e incumbe profissionais no seu gerenciamento.

O prêt-à-porter, assim, revolucionou o varejo de moda ao acessibilizar o estilo/marca antes restrito a Alta Costura. Embora os americanos estivessem à frente dos franceses no domínio da técnica de produção industrial, foi no "nascimento das butiques independentes [que se] deu início a uma verdadeira revolução nas compras" (JONES, 2005, p.41), isto é, o varejo expandiu, aumentando a competitividade e proliferando as cadeias de lojas que exigiam uma certa padronização e identidade próprias.

\subsubsection{Quarta Fase - Experiencial (1980 a 2010)}

A partir da década de 1980 instaura-se a lógica do consumo emocional, fundamentalmente pautada através das marcas "que gabam os méritos das iniciativas que proporcionam aos consumidores: experiências afetivas, imaginárias e sensoriais" (LIPOVETSKY, 2007, p. 39), em que, segundo Lipovetsky (2007, p. 39), "já não é a funcionalidade fria que está na ordem do dia, mas a atratividade sensível e emocional".

Para Lipovetsky (2007) o que levou as relações de consumo a esse nível hedonista foi a forma como a publicidade erotizou os produtos, criando um ambiente festivo, um clima de sonho acordado e de estimulação permanente dos desejos. “É o que se verifica ainda. Assistimos à teatralização dos pontos de venda [...] com o objetivo de criar ambiências de convivialidade e de desejos, de associar o prazer à frequentação dos espaços de venda" (LIPOVETSKY, 2007, p. 57).

Esse cenário possibilitou que o chamado consumidor hedonista, historicamente restrito ao mercado de luxo, se massificasse no século XXI, demandando da comunicação de marketing (comar) novas perspectivas de estimulação, associadas ao visual merchandising e alinhadas as práticas de Comunicação Integrada de Marketing (CIM), estudos do comportamento do shopper', desenvolvimento do marketing sensorial e da psicologia ambiental.

1 Shopper é um conceito usado para identificar o consumidor no ato efetivo da compra e que, naturalmente, pode ser um consumo para outros (presentes), servindo também para distinguir o conceito de comprador profissional (D’ANDREA et al., 2011).

Projética, Londrina, v.9, n.2, p. 39-54, Jul./Dez. 2018 
Assim, a comunicação através do PDV assume papel destacado na comar, sendo o "elo principal que conecta a marca, o consumidor, o produto e o ambiente [...]" (BAILEY; BAKER, 2014, p.10).

As flagship store surgem nas décadas de 1920 e 1930 através das maisons da Alta Costura, mas é na década de 1960, particularmente em Milão e Londres, que as lojas de varejo independentes tiveram a necessidade competitiva de desenvolver um design inovador para o PDV (MORES, 2007 apud NOBBS et al., 2012, p. 923). Sobretudo, foi na década de 1980 que "as marcas perceberam que havia um 'gap' entre elas e seus consumidores finais e decidiram que era necessário mostrar o que a marca é e para onde ela pretendia ir" (OMINE, 2009, s.p.).

A extensão do número de diferentes categorias de produtos no portfólio das marcas, como artigos para o lar, obrigou os varejistas a trabalharem com o conceito de lifestyle (BINGHAM, 2005 apud NOBBS et al. 2012, p. 923). As marcas de luxo foram assim forçadas a evoluir no sentido de oferecer uma experiência de marca diferenciada para o cliente cada vez mais exigente e um mercado cada vez mais competitivo (TUNGATE, 2008 apud NOBBS et al. 2012, p. 923).

Sackrider et al. (2009, p.28) apontam quatro elementos como responsáveis pelo desenvolvimento do visual merchandising no Século XX: "a evolução da distribuição, as modificações do comportamento do consumidor, a banalização dos produtos e o crescimento da concorrência". Esses aspectos foram fundamentais na formação de um novo modelo de gestão chamado fast fashion.

O modelo fast fashion concentra seus esforços na principal atividade empresarial e terceiriza as atividades secundárias, verticalizando praticamente toda a cadeia produtiva. Essa integração vertical possibilita às empresas maior rapidez na criação, produção, distribuição e comercialização dos produtos. Assim, segundo Ghemawat e Nueno (2003), o fast fashion está fundamentado em três pilares: produtos com forte apelo de moda; constante geração da sensação de escassez nos clientes; e altos investimentos em visual merchandising.

Demetresco (2007) acrescenta à relevância do PDV o papel das vitrinas, pois com o desenvolvimento das estratégias de marketing das marcas e a crescente importância do ponto de venda, consequentemente as vitrinas tornaram-se relevantes no Composto de Marketing, como se observa no caso das lojas conceito (concept store) e nas lojas de fast fashion, pois tornaram-se um elemento-chave já que "é por meio delas [vitrinas] que se pode ter uma experiência concreta e direta da marca e de seu produto" (DEMETRESCO, 2007, p. 202). 


\subsubsection{Quinta Fase - Eletrônica (a partir de 2010)}

Definir historicamente um período ainda em vigência é um trabalho tendencioso pela total falta de percepção do todo, porém, as novas tecnologias aceleraram de tal forma os processos sociais, de consumo e mercadológicos que seria parcial uma análise que não incluísse o mundo virtual em suas discussões.

A convenção anual Retail Big Show da National Retail Federation (NRF) é a maior referência para o varejo global e tem apontado em suas análises e perspectivas de tendências que os maiores desafios do varejo off-line se concentram na necessidade de integração com o mundo digital e na oferta de experiências significativas para o shopper (SERRENTINO, 2013). O autor ainda afirma que "pontos de venda têm o poder de reinventar e dar valor a produtos, gerar estímulos sensoriais, provocar emoção e promover experiências. Para que as pessoas continuem querendo comprar em lojas, elas terão que ser estimulantes e envolventes" (s.p.).

Ainda que a internet seja uma invenção do século passado, foi a popularização dos smartphones em $2010^{2}$ e a entrada da geração de nativos digitais ao mercado de consumo que proporcionaram significativa alteração no comportamento do consumidor, ao permitir acesso ininterrupto e em trânsito desses indivíduos multimídias à web.

Conforme avançamos no século XXI, a tecnologia que torna nossas experiências de compra mais rápidas, mais inteligente, mais informadas, mais interativas e, acima de tudo, mais cativantes está se tornando mais avançada e sofisticada. Essa tecnologia nos leva não só ao mundo virtual, mas também aumenta a experiência na loja física. (BAILEY; BAKER, 2014, p.162)

Para Bailey e Baker (2014) a tecnologia eletrônica tem a função no varejo de simplificar a experiência de compra e facilitar a venda, no entanto, o visual merchandising ainda não explorou totalmente as possibilidades. $O$ pouco que se vê no varejo são paredes de tecnologia cinética, som digital, espelhos virtuais, cabides, pisos, escadas e manequins digitais, etiquetas e chips RFID (Radio-Frequency Identification), projeção imersiva em 360 graus, mas ainda tudo de forma tímida e experimental. "O consumidor dos dias de hoje [...] está bem informado e sempre conectado [...] e os jornais, revistas e outdoors de propaganda não são mais suficientes para prender sua atenção [...]" (BAILEY; BAKER, 2014, p. 162), daí a necessidade de novos estímulos de comunicação de marketing no ponto de venda.

2 Em apenas três anos, segundo análise da consultoria International Data Corporation (IDC), o mercado mundial de smartphones cresceu 146\%, passando de 124 milhões de unidades em 2007 para 305 milhões em 2010. 


\section{RESULTADOS E DISCUSSÃO}

Os resultados dessa análise de perspectiva histórica do desenvolvimento do visual merchandising parecem definir as suas práticas em cinco grandes fases (Figura 1), traçando uma timeline que reflete as alterações sofridas na atmosfera de loja ao longo do tempo.

Conforme observou-se na revisão bibliográfica, os espaços comerciais demandaram cada vez mais as variáveis do escopo da atmosfera proposto por Turley e Milliman (2000). Nesse quase um milênio de história do varejo, aumentaram-se as competências e habilidades inerentes à área na medida em que se desenvolveram o mercado consumidor, a concorrência varejista e as tecnologias relativas ao varejo, incumbindo ao visual merchandiser a responsabilidade pela gestão dessa complexa atmosfera de loja.

Figura 1. Fases da evolução da atmosfera de loja para o visual merchandising.

\begin{tabular}{|c|}
\hline $\begin{array}{c}\text { Primeira Fase } \\
\text { - Estrutural }\end{array}$ \\
\hline $\begin{array}{c}\text { Exposição dos } \\
\text { produtos }\end{array}$ \\
\hline Arcadas \\
\hline Vitrinas
\end{tabular}
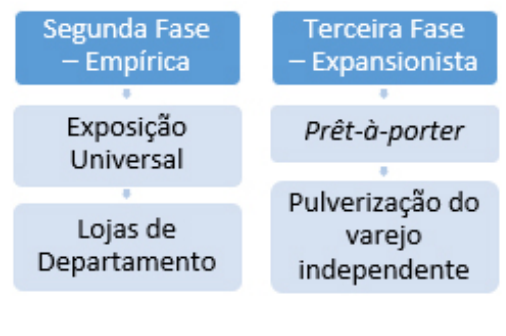

Quinta Fase
- Eletrônica
$\begin{gathered}\text { Simplificação da } \\ \text { jornada de } \\ \text { compra }\end{gathered}$
Estimulação
através do digital

Fonte: elaborado pelos autores (2017).

A falta de detalhes sobre as primeiras incursões do varejo é um limitador à pesquisa, por isso, a estrutura de cinco fases é apontada como provisória enquanto outros estudos não trazem luz à períodos específicos dessa análise, principalmente a Primeira Fase (Estrutural) que se refere a $82,2 \%$ da distribuição do tempo entre as fases da evolução do varejo. Dessa forma, ressalta-se nos resultados e discussão o fluxo de análise sob o viés pragmático para a teorização, acompanhando a dinâmica de uma ferramenta essencialmente mercadológica.

A primeira fase (Estrutural) remete aos primórdios da exposição de produtos. Um contexto de pouca competição comercial e um restrito mercado consumidor. Os incentivos para o desenvolvimento do varejo eram, portanto, baixos. Ainda que não houvesse formalmente o conceito de visual merchandising nesse período, a prática por si só já nasce com o varejo, desde a seleção, coordenação e apresentação dos produtos. "Seria talvez possível, lembrando os saltimbancos das feiras da Idade Média ou grandes mercadores do Renascimento, basear em algumas práticas inatas de valorização de seus produtos as premissas do merchandising atual" (SACKRIDER et al., 2009, p. 27). 
É na segunda fase (Empírica), no entanto, que se consolidam as primeiras preocupações com a capacidade de a atmosfera de loja despertar desejos de consumo e aumentar a percepção de valor dos produtos. Os inventos oriundos da Revolução Industrial exigiram maiores esforços de divulgação e valorização, além do despertar de uma cultura de consumo (BARBUY, 1999). Nesse contexto, as poucas variáveis da atmosfera de loja são testadas de forma empírica e a exposição de produtos começa a transpor o apelo estéticovisual para a ambientação das lojas, com a finalidade de decorar os ambientes comerciais, narrando uma história de origem e valorização dos produtos.

A terceira fase (Expansionista) consolida-se como o período de maior desenvolvimento das técnicas de visual merchandising e, portanto, abarca uma maior gama de variáveis que estão no escopo da área, haja vista que a expansão do varejo e das cadeias de lojas exigiram uma tentativa de padronização dos pontos de venda, de forma que refletissem o posicionamento das marcas e, ao mesmo tempo, atendessem as expectativas de um novo público consumidor. Os profissionais de visual merchandising ainda precisaram estimular o consumo dos produtos oriundos do prêt-à-porter e evidenciar as marcas (muitas recém-lançadas) através de uma identidade visual. A profissionalização do varejo através do modelo prêt-à-porter, o aprimoramento do gerenciamento de marketing com a difusão do conceito de marca, os estudos acerca do comportamento do consumidor e, principalmente, o autosserviço no pósGuerra aumentaram a relevância do PDV na comunicação de marketing.

A quarta fase (Experiencial) configura, de fato, uma revolução no conceito de visual merchandising, pois o consumo emocional direciona as ações de comunicação de marketing para uma prática de experiências significativas, integradas e/ou sensoriais, logo, o VM passa a ganhar relevância no segmento de bens hedônicos.

A quinta fase (Eletrônica) ainda está em curso, mas as evidencias já apontam para o uso das tecnologias eletrônicas com o propósito de facilitar a jornada de compra, melhorar a experiência de compra e aumentar a reciprocidade do consumidor.

A dinâmica que originou o modelo do fast fashion também demanda do VM novidades num clico de vida cada vez mais efêmero; novidades estas que devem refletir também em toda ambientação das lojas, haja vista que, segundo Mesquita e Castilho (2004), a mudança na aparência gera aparência de mudança. Assim, o visual merchandising vai incrementar objetivos estratégicos conforme suas fases de evolução. 
Figura 2. Objetivos do visual merchandising por fase.

\begin{tabular}{|c|c|c|c|c|}
\hline $\begin{array}{c}\text { Primeira Fase - } \\
\text { Estrutural }\end{array}$ & $\begin{array}{c}\text { Segunda Fase - } \\
\text { Empírica }\end{array}$ & $\begin{array}{c}\text { Terceira Fase } \\
\text { Expansionista }\end{array}$ & $\begin{array}{c}\text { Quarta Fase } \\
\text { Experiencial }\end{array}$ & $\begin{array}{c}\text { Quinta Fase - } \\
\text { Eletrônica }\end{array}$ \\
\hline Exibitécnica & Exibitécnica & Exibitécnica & Exibitécnica & Exibitécnica \\
\hline & Tematização & Tematização & Tematização & Tematização \\
\hline & $\begin{array}{c}\text { Identidade visual } \\
\text { da marca }\end{array}$ & $\begin{array}{c}\text { Identidade visual } \\
\text { da marca }\end{array}$ & $\begin{array}{c}\text { Identidade visual } \\
\text { da marca }\end{array}$ \\
\hline
\end{tabular}

Fonte: elaborado pelos autores (2017).

O conceito inicial que era restrito a exposição de produtos no PDV na fase Estrutural, incrementa na fase Empírica o desenvolvimento de ambientes temáticos para valorização da mercadoria. Já na fase Expansionista se torna uma ferramenta de comunicação mercadológica, sendo, por isso, um dos constructos a serem explorados pelo branding, uma vez que atua na construção de uma identidade visual para a marca. Mas é na fase Experiencial que atinge o ápice das variáveis proposta por Turley e Milliman (2000). E, por fim, na fase Eletrônica a cultura cibernética também passa a ser assimilada nos processos de VM, sendo o PDV um relevante ponto de contado da marca, capaz de atrair, dialogar, significar e facilitar a comunicação com os consumidores.

\section{CONSIDERAC̣ÕES FINAIS}

Conforme o proposto, este estudo estabeleceu (ainda que de forma preliminar) uma evolução histórica da atmosfera de loja dos espaços comerciais destinados à comercialização de artigos têxteis e de moda para compreender as ressignificações do visual merchandising.

A timeline de cinco fases (estrutural, empírica, expansionista, experiencial e eletrônica) apresentada evidencia que, à medida que os processos industriais se desenvolveram e a cultura de consumo se consolidou, a loja tornou-se muito mais do que um mero canal de comercialização de produtos, demandando, por isso, mais estímulos para manter-se relevante ao shopper - responsabilidade essa atribuída ao visual merchandising.

Logo, se a administração de marketing adotou uma perceptiva de "fora para dentro" (KOTLER, 2005, p.14) e já reconhece a posição central do consumidor nas suas decisões estratégicas, não obstante o foco do visual merchandising na contemporaneidade deslocou-se da consequência para sua causa, isto é, as vendas não são mais o enfoque principal, mas seu escopo de atuação tem como foco o branding. 


\section{REFERÊNCIAS}

BARBUY, Heloisa. A Exposição Universal de 1889 em Paris. São Paulo: Edições Loyola, 1999.

BAILEY, Sarah; BAKER, Jonathan. Moda e visual merchandising. São Paulo: Editora Gustavo Gilli Brasil, 2014. Coleção GGmoda.

BENJAMIN, Water. The Arcades Project. New York: Belknap Press, 2002.

BERMAN, Barry; EVANS, Joel R. Retail Management: a strategic approach. Englewood Cliffs: Prentice-Hall, 1995.

BLESSA, Regina. Merchandising no ponto-de-venda. São Paulo: Editora Atlas, 2009.

BHALLA, Swati. SINGHAL, Anuraag. Visual merchandising. New Delhi: Tata McGraw-Hill, 2010.

CRESCITELLI, E.; SHIMP, T.A. Comunicação de marketing - Integrando propaganda, promoção e outras formas de divulgação. São Paulo: Cengage, 2012.

D'ANDREA, Rafael; CÔNSOLI, Matheus Alberto; GUISSONI, Leandro Angotti. Shopper Marketing: a nova estratégia integrada de marketing para a conquista do cliente no ponto de venda. São Paulo: Atlas, 2011.

DEMETRESCO, Sylvia. Visual Merchandising e Marketing de moda. In: COBRA, Marcos. Marketing \& Moda. São Paulo: Editora SENAC e Cobra Editora e Marketing, 2007.

EBSTER, Claus; GARAUS, Marion; MALHOTRA, Naresh (org.). Design de loja e merchandising visual: criando um ambiente que convida a comprar. São Paulo: Saraiva, 2013.

GHEMAWAT, Pankaj; NUENO, José Luis. Artigo científico: ZARA: fast fashion. Estudo de caso da Universidade de Harvard Business School. Estados Unidos, Boston, HBS Case Study 9-703-497. Dezembro de 2003. Disponível em: <http://wehner.tamu.edu/mgmt.www/v-buenger/466/zara.pdf> Acesso em: 14/04/2017.

JONES, Sue Jenkyn. Fashion Design: manual do estilista. São Paulo: Cosac Naify, 2005.

KOSMINSKY, Doris Clara; CIPINIUK, Alberto; VILLAS BÔAS, Glaucia. O olhar inocente é cego: a construção da cultura visual moderna. 2008. Tese (Doutorado) - Pontifícia Universidade Católica do Rio de Janeiro, Departamento de Artes \& Design, 2008 Disponível em: <http://www2. dbd.puc-rio.br/pergamum/biblioteca/php/mostrateses.php?open=1\& arqtese=0410914_08_Indice.html>. Acesso em: 14 abrir 2017.

KOTLER, Philip. Marketing essencial: conceitos, estratégias e casos. São Paulo: Prentice Hall, 2005. 
KOTLER, Phillip. Atmospherics as a Marketing Tool. Journal of Retailing. Winter 73/74, Vol. 49 Issue 4, p.48, 1973.

LAS CASAS, Alexandre Luzzi. Marketing de Varejo. São Paulo: Editora Atlas, 1992.

LEÃO, Joelma. A Engenharia da Moda e os Programas das TVs por assinatura: análise das tendências de moda Primavera/Verão 97 através dos estudos de casos das empresas "Promostyl', "Ciba" e "Du Pont" e os programas "86-6086" e "Style". 2001. 476 f. Dissertação (Mestrado em Multimeios). Instituto de Artes, Universidade Estadual de Campinas, Campinas, 2001.

LIPOVETSKY, Gilles. A Felicidade Paradoxal: ensaio dobre a sociedade de hiperconsumo. Lisboa: Edições 70, 2007.

MESQUITA, Cristiane. CASTILHO, Kathia (coord.). Moda contemporânea: quatro ou cinco conexões possíveis. São Paulo: Editora Anhembi Morumbi, 2004. (Coleção moda e comunicação).

MCMILLAN, John. A reinvenção do bazar: uma história dos mercados. Rio de Janeiro: Jorge Zahar, 2004.

MORGAN, Tony. Visual Merchandising - vitrines e interiores comerciais. São Paulo: Gustavo Gili, 2011.

NOBBS, Karinna; MOORE, Christopher M.; SHERIDAN, Mandy. The flagship format within the luxury fashion Market. In: International Journal of Retail \& Distribution Management, (2012) Vol. 40 Iss 12 pp. 920 - 934.

PEGLER, Martin M. Merchandising Visual e Display. New York, US: Bloomsbury Academic, 2000.

SACKRIDER, Françoise; GUIDÉ, Gwenola; HERVÉ, Dominique. Entre vitrinas: distribuição e visual merchandising na moda. Tradução de Ana Luiza Ramazzina e Regina Carrara. São Paulo: Editora SENAC São Paulo, 2009.

SERRENTINO, Alberto. A loja do futuro em 10 pontos. Disponível em: < http:// www.mundodomarketing.com.br/inteligencia/estudos/78/a-loja-do-futuroem-10-pontos.html>. Acesso em 22/04/2017.

TURLEY, L.W.; MILLIMAN, R.E. Atmospheric effects on shopping behavior: a review of the experimental evidence. Journal of Business Research, v.49, p.193$211,2000$.

OMINE, Helena. Conceitos na vitrine: A concept store é a nova aposta das empresas para atrair consumidores. São Paulo: 2009. Revista Propaganda. Agosto de 2009. Entrevista concedida a Renata Guerra.

WILLIAMS, Paul. O guia completo das cruzadas. São Paulo: Madras, 2007. 